Provided for non-commercial research and education use. Not for reproduction, distribution or commercial use.

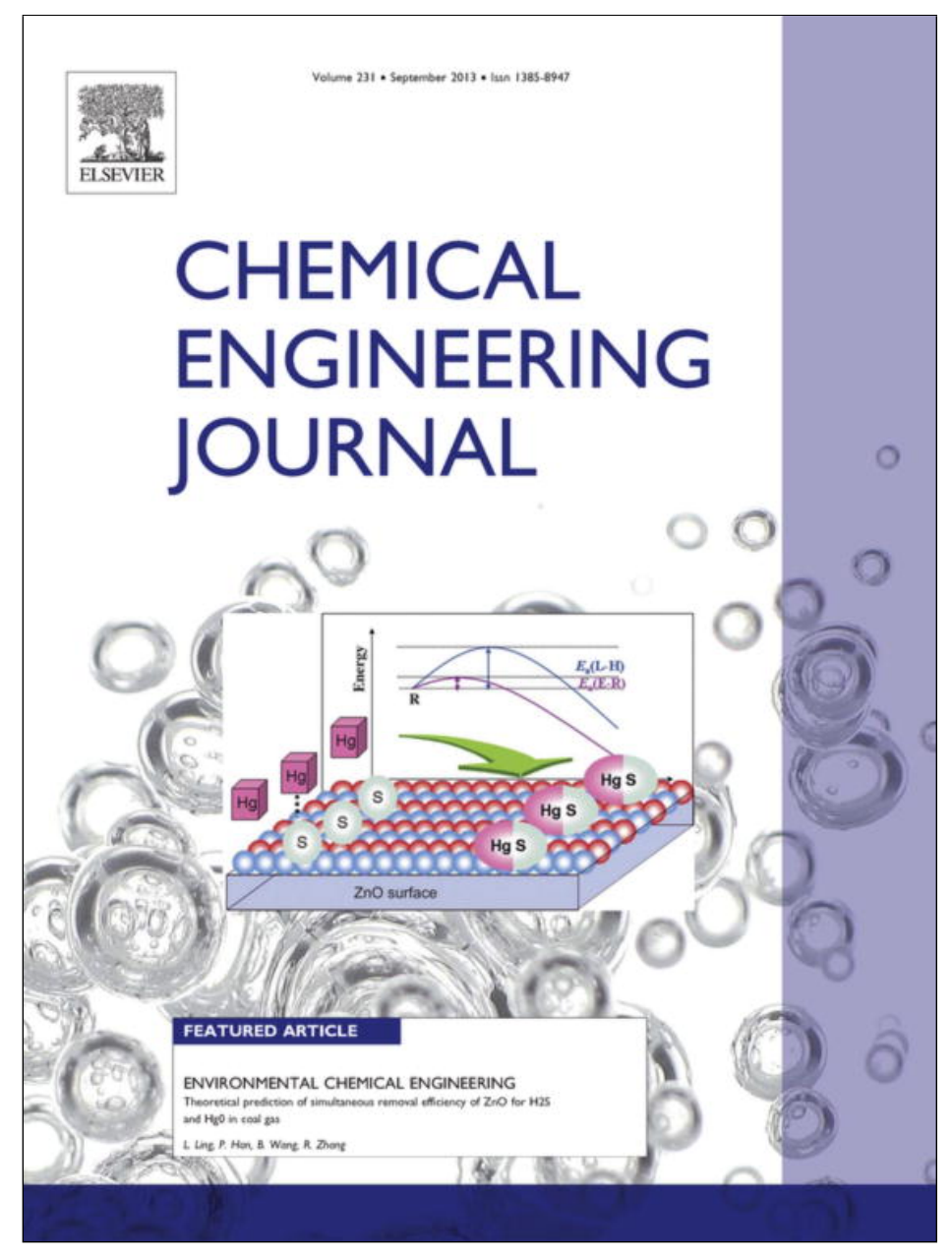

This article appeared in a journal published by Elsevier. The attached copy is furnished to the author for internal non-commercial research and education use, including for instruction at the authors institution and sharing with colleagues.

Other uses, including reproduction and distribution, or selling or licensing copies, or posting to personal, institutional or third party websites are prohibited.

In most cases authors are permitted to post their version of the article (e.g. in Word or Tex form) to their personal website or institutional repository. Authors requiring further information regarding Elsevier's archiving and manuscript policies are encouraged to visit:

http://www.elsevier.com/authorsrights 


\title{
Recovery of catechin and epicatechin from sago waste effluent: Study of kinetic and binary adsorption isotherm studies
}

\author{
Felycia Edi Soetaredjo ${ }^{a}$, Suryadi Ismadji ${ }^{b}$, Shella Permatasari Santoso ${ }^{a}$, Ong Lu Ki ${ }^{\text {b }}$, Alfin Kurniawan ${ }^{\text {b }}$ \\ $\mathrm{Yi}-\mathrm{Hsu} \mathrm{Ju}{ }^{\mathrm{a}, *}$ \\ ${ }^{a}$ Department of Chemical Engineering, National Taiwan University of Science and Technology, 43, Sec 4., Keelung Rd., Taipei, Taiwan \\ ${ }^{\mathrm{b}}$ Department of Chemical Engineering, Widya Mandala Surabaya Catholic University, Kalijudan 37, Surabaya 60114, Indonesia
}

\section{H I G H L I G H T S}

- Recovery of catechin and epicatechin from sago waste effluent.

- Supercritical $\mathrm{CO}_{2}$ desorption of catechin and epicatechin from activated carbon.

- Adsorption of catechin and epicatechin in binary system.

\section{A R T I C L E I N F O}

\section{Article history:}

Received 27 May 2013

Received in revised form 16 July 2013

Accepted 17 July 2013

Available online 26 July 2013

\section{Keywords:}

Catechin

Epicatechin

Binary adsorption

Supercritical $\mathrm{CO}_{2}$ extraction

\begin{abstract}
A B S T R A C T
The recovery of valuable phenolic compounds (catechin and epicatechin) from sago waste effluent by activated carbon adsorption was studied in this work. Single and binary component of catechin and epicatechin was studied in static mode using synthetic effluent. Langmuir model was applied to evaluate the adsorption equilibrium data in single system. In binary system, the modified extended Langmuir model by inclusion of surface coverage was used to represent the adsorption data. All experimental data were well represented either by Langmuir model or its modified form. For kinetic study, it was found that pseudo-second order model represents the experimental data better than pseudo-first order model. Adsorption study using real sago waste effluent indicated that activated carbon adsorption process is promising for recovery of valuable phenolic compounds. Supercritical $\mathrm{CO}_{2}$ extraction of phenolic compounds from activated carbon resulted in low recovery. The addition of ethanol as co-solvent significantly enhanced the desorption of catechin and epicatechin from activated carbon.
\end{abstract}

(c) 2013 Elsevier B.V. All rights reserved.

\section{Introduction}

Phenolic compounds are universally distributed in plants such as leave, trunk, root, seed, and fruit. They are usually are bounded within plant tissues. Phenolic compounds as antioxidants are believed to contribute to health benefits through several possible mechanisms such as by quenching free radicals, chelating transition metals, reducing peroxides and stimulating antioxidative enzyme defense. Natural antioxidants are known to exhibit a wide range of biological effects including anti-bacterial, antiviral, antiinflammatory, anti-allergic, antithrombotic and vasodilatory activities [1]. The antioxidant activity of phenolic compounds is mainly attributed to their redox properties, which allow them to act as reducing agents, hydrogen donors and quenchers of singlet oxygen. In addition, they may also possess metal chelating properties. Phenolic compounds possess aromatic structure along with hydroxyl

\footnotetext{
* Corresponding author. Tel.: +886 (2) 27376611 ; fax: +886 (2) 27376644.

E-mail address: yhju@mail.ntust.edu.tw (Y.-H. Ju).
}

substituent which enable them to protect human tissues from damages caused by oxygen or free radicals, and consequently reduce the risk of various diseases, and offer beneficial effect against cancer, cardiovascular disease, diabetes, and Alzheimer's disease [2-7].

In starch extraction from sago pith, the sago pith slurry during sedimentation is browning due to the oxidation of phenolic compounds by the polyphenol oxidase (PPO) enzyme [8]. Phenolic compounds are located mainly in vacuoles while the PPO is found in plastids. Browning is initiated with the disruption of cell due to cutting or bruising and the compartmentalization is lost. The primary phenolic compounds related to browning are DL-epicatechin and D-catechin [8,9]. Pei-Lang et al. [9] reported that the content of phenolic compounds in sago pith depends on its growth stages and height; and the amount of phenolic compound extracted is less than $1 \%$.

Recovery of phenolic compounds from the waste effluents is beneficial, but it is a challenging process. Adsorption is efficient for removing organic matter from waste effluents. Activated 
carbons are the most widely used adsorbents due to their high adsorption capacities for organic pollutants which are related to their high surface area, pore volume and porosity. The adsorption capacities also strongly depend on the activation method and the nature of source materials. Activated carbon is an effective adsorbent for organic compounds removal, especially for phenolic compounds [10-15]. However, the utilization of activated carbon as adsorbent in the adsorption of epicatechin and catechin has never been reported.

The focus of this work was to evaluate the adsorption performance of activated carbon for the recovery of epicatechin and catechin in single and binary component systems. The surface area was obtained based on Brunauer, Emmet, and Teller (BET) measurements, while the pore volume and pore diameter of activated carbon were calculated from the adsorption experimental data using density functional theory (DFT). The effect of various variables, such as initial adsorbate concentrations, adsorption time and mass of adsorbent were studied using batch equilibrium technique. Pseudo first and second order kinetic models were used to correlate the adsorption dynamic or kinetic data. The adsorption equilibrium data was evaluated using Langmuir model for single component, while modified extended-Langmuir model with incorporation of solute's selectivity factor was used to study the correlation [16]. The feasibility and adsorption performance of activated carbon in recovering epicatechin and catechin was also tested in real effluent.

\section{Experimental section}

\subsection{Chemicals}

HPLC grade (-)-epicatechin (purity $98 \mathrm{wt} . \%)$ and (+)-catechin hydrate (purity $\geqslant 98$ wt.\%) were obtained from Sigma Aldrich (Singapore) and was used without any further purification. Pellet activated carbon $(0.5-1.5)$ produced by Norit (The Netherland) was used as the adsorbent. Double distilled water was used in adsorption experiments.

\subsection{Characterizations of activated carbon}

Since structural heterogeneity of activated carbon plays an important role during adsorption therefore it is crucial to characterize the pore structure of activated carbon. Pore structure of the activated carbon was characterized by nitrogen sorption technique in a Quadrasorb SI at boiling point of nitrogen gas $\left(-196^{\circ} \mathrm{C}\right)$. Prior to the nitrogen sorption measurement, the activated carbon was degassed in vacuum condition at $200{ }^{\circ} \mathrm{C}$ for $48 \mathrm{~h}$. The measurement of the nitrogen sorption isotherms (adsorption and desorption) were conducted over a relative pressure $\left(p / p_{0}\right)$ of $0.001-$ 0.990 . The BET surface area of the carbon was determined by standard BET equation at a relative pressure of $0.06-0.3$. Total of pore volume of the activated carbon was evaluated at the highest relative pressure (0.990). At this relative pressure all pores within the activated carbon were already completely filled with nitrogen gas. Pore size distribution of the carbon was determined by standard DFT method with medium regularization.

\subsection{Static adsorption experiments}

The adsorbate solution was prepared by mixing a known amount of adsorbate ((-)-epicatechin or (+)-catechin hydrate) with double distilled water to produce the desired initial concentrations (100-150 mg/L). The adsorption was carried out isothermally in static mode at $303.15 \mathrm{~K}$. A fixed amount of activated carbon was added to a series of $250 \mathrm{~mL}$ glass-stoppered flasks each filled with $100 \mathrm{~mL}$ diluted solutions. The glass stoppered flasks were then put in a thermostatic shaker bath at $120 \mathrm{rpm}$ for $1 \mathrm{~h}$ (the equilibrium condition was achieved in about $40 \mathrm{~min}$ ). The adsorption isotherm for binary systems of epicatechin and catechin was also obtained isothermally at $303.15 \mathrm{~K}$, using the same procedure as for the single component adsorption.

To study the adsorption kinetics, a series of $250 \mathrm{~mL}$ glass-stoppered flasks contained $100 \mathrm{~mL}$ of phenolic compound solution with certain initial concentration $(100-250 \mathrm{mg} / \mathrm{L})$ were prepared. Subsequently, a known amount of activated carbon ( $0.2 \mathrm{~g}$ ) was added into each glass-stopper flask. The glass-stopper flasks were placed in thermostatic water-bath shaker for 150 min at $303.15 \mathrm{~K}$. During kinetic experiments, at intervals of $10 \mathrm{~min}$, one of glass-stopper flask was taken and the concentration of phenolic compound was analyzed.

The adsorption of phenolic compounds from waste effluent was carried out using waste water from sago starch extraction. Briefly, sago pith was pulverized into coarse powder and soaked in water $(1 \mathrm{~h})$, and then filtered using Buchner funnel to obtain the waste effluent. One gram of activated carbon was added to $250 \mathrm{~mL}$ glass-stopper flasks each filled with $100 \mathrm{~mL}$ waste effluent. The glass stopper flask was placed in a thermostatic shaker bath at $120 \mathrm{rpm}$ for $1 \mathrm{~h}$.

The initial and equilibrium concentrations of the single and binary solutions and waste effluent were analyzed using a HPLC (Jasco HPLC PU-2089 plus) with a UV-vis detector (UV-2077 plus) set at $280 \mathrm{~nm}$. Separations were achieved in an Enduro C18, $5 \mu \mathrm{m}$, $250 \times 4.6 \mathrm{~mm}$. The flow rate was $0.8 \mathrm{ml} / \mathrm{min}$. The mobile phase used was isocratic elution comprised of $3 \%$ acetic acid in double distilled water (60\%) and acetonitrile ( $40 \%$ ) for a total running time of $10 \mathrm{~min}$. The contents of epicatechin and catechin were determined using calibration curves.

The effect of $\mathrm{pH}$ on the adsorption of epicatechin and catechin was investigated in single component systems. It was found that as the initial solution $\mathrm{pH}$ was reduced to $\mathrm{pH} 3$, the solution concentration decreased up to $50 \%$ of the initial concentration. When the initial solution $\mathrm{pH}$ was increased to $\mathrm{pH} 10$, the solution concentration also decreased up to $60-70 \%$ of the initial concentration. This is due to oxidation of the phenolic compounds. Therefore, the adsorption of epicatechin and catechin in single and binary component were carried out at $\mathrm{pH} 7$, which is similar to the waste effluent $\mathrm{pH}$.

\subsection{Calculations}

The amounts of epicatechin and catechin adsorbed onto activated carbon in single component system were calculated using the following equation:

$q_{e}=\frac{\left(C_{0}-C_{e}\right)}{m} \times V$

where $C_{0}$ and $C_{e}$ are the initial and equilibrium concentration of phenolic compounds in the liquid phase $(\mathrm{mg} / \mathrm{L})$, respectively, $V$ is the volume of phenolic compounds solution (L), $q_{e}$ is the amount of metal ions adsorbed per unit of biosorbent mass $(\mathrm{mg} / \mathrm{g})$, and $m$ is the mass of activated carbon ( $\mathrm{g}$ ). The equilibrium concentration of phenolic compound $i$ species $\left(C_{e, i}\right)$ in binary mixture was calculated by the same manner using following mass balance equation:

$q_{e, i}=\frac{\left(C_{0, i}-C_{e, i}\right)}{m} \times V$

where $q_{e, i}$ is the equilibrium amount of solute $i$ in the adsorbed phase (mg/g), $C_{0, i}$ and $C_{e, i}$ are the initial and equilibrium concentration of solute $i$ in the liquid phase $(\mathrm{mg} / \mathrm{L})$, respectively. All data are the average results of triplicates experiments. 


\section{Results and discussion}

\subsection{Activated carbon characterization}

Analysis of nitrogen sorption isotherms and DFT-pore size distribution of the activated carbon used in this study indicates that the NORIT carbon possess both micropore and mesopore structures with micropore structure more dominant than mesopore as indicated by the rapid filling of pores at low relative pressure and followed by the gradual increase of adsorption at moderate relative pressure (S1). The existence of the mesopores is indicated by the presence of hysteresis loop between adsorption and desorption isotherms, an indication of capillary condensation in the mesopores. The BET surface area, micropore volume, and total pore volume of the activated carbon (NORIT nrs carbon Ea 0.5-1.5) were $890 \mathrm{~m}^{2} / \mathrm{g}, 0.431 \mathrm{~cm}^{3} / \mathrm{g}$, and $0.506 \mathrm{~cm}^{3} / \mathrm{g}$, respectively.

The pore distribution of activated carbon represents a model of carbon internal structure which represents non-interacting of regularly shape model pores and complex void spaces within the carbon. The pore size distribution of the carbon is one of its most important characteristics of the carbon in studying adsorption equilibrium and kinetic. The pore size distribution of the activated carbon confirms that the carbon possesses both micropore and mesopore structure (S2).

\subsection{Adsorption isotherms}

The isotherm shape can be used as quasi-qualitative information on the nature of the solute-surface interaction. In the case of adsorption of phenolic compounds from water, it is characterized by initial region (high uptake at low concentration); and Langmuir model is best fitted for this case $[17,18]$. Based on the classification proposed by Giles et al. [17,18], the curve shape in Fig. 1 is class L2 according to the Giles classification suggests that the aromatic ring adsorbed is parallel to the surface and no strong competition exists between the adsorbate and the solvent to occupy the adsorption sites [12]. Langmuir isotherm is characterized by a plateau curve which indicates that equilibrium has been achieved. The Langmuir isotherm was originally developed for describing gas adsorption phenomena but it has been extensively used for the correlation of adsorption equilibrium data of various solute-sorbent interactions in liquid phase [19-21]. The Langmuir isotherm model is given as follows:

$q_{e}=q_{m} \frac{K_{L} \cdot C_{e}}{1+K_{L} \cdot C_{e}}$

where $q_{m}$ is the maximum adsorption capacity of the solid ( $\mathrm{mg} / \mathrm{g}$ ) corresponding to monolayer surface coverage and $K_{L}$ is Langmuir constants of adsorption affinity $(\mathrm{L} / \mathrm{mg})$.

Fig. 1 shows that the adsorption equilibrium data of phenolic compounds are well fitted by the Langmuir isotherm model and the correlation coefficients for epicatechin and catechin are 0.97 and 0.94 , respectively. The maximum adsorption capacity $\left(q_{m}\right)$ of catechin $(73.56 \mathrm{mg} / \mathrm{g})$ obtained by fitting calculation using SigmaPlot 12.0 is higher than that of epicatechin $(29.04 \mathrm{mg} / \mathrm{g})$. The adsorption affinity parameter $\left(K_{L}\right)$ of catechin and epicatechin obtained are $0.1257 \mathrm{~L} / \mathrm{mg}$ and $0.041 \mathrm{~L} / \mathrm{mg}$, respectively. Higher adsorption affinity parameter of catechin than epicatechin indicates that catechin is easier adsorbed onto the surface interior of the carbon.

Industrial Adsorption process usually involves multi-component, therefore, information on adsorption equilibria in multi-component system is required for engineering design of the adsorption process. Compare to the single component adsorption, reliable experimental multi-component adsorption isotherm data are more
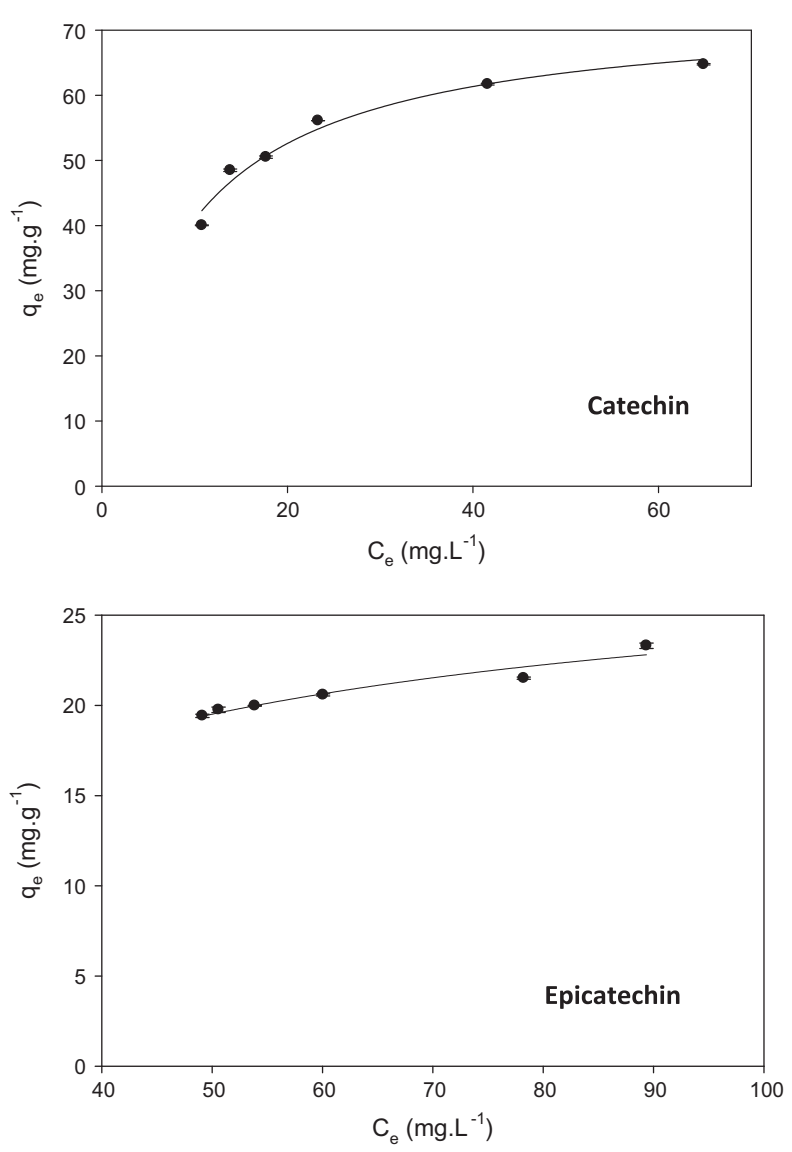

Fig. 1. Adsorption isotherm of catechin and epicatechin onto activated carbon NORIT nrs carbon Ea 0.5-1.5 and Langmuir isotherm model (solid lines).

time consuming and much more difficult to obtain. Therefore it will be convenient if the multi-component isotherm can be constructed based on single adsorption isotherms. Various models have been developed for this purpose and one of the most widely used is the extended Langmuir and its modified forms $[16,22,23]$. The extended Langmuir model for a two-component system can be expressed as:

$q_{e, 1}=\frac{q_{m, 1} K_{L, 1} C_{e, 1}}{1+K_{L, 1} C_{e, 1}+K_{L, 2} C_{e, 2}}$

$q_{e, 2}=\frac{q_{m, 2} K_{L, 2} C_{e, 2}}{1+K_{L, 1} C_{e, 1}+K_{L, 2} C_{e, 2}}$

where $q_{m, i}$ and $C_{e, i}$ are the amount adsorbed and equilibrium concentration of component $i$, respectively. The parameters $q_{m, i}$ and $K_{L, i}$ are the adsorption capacity of component $i$ in the adsorbent and adsorption affinity of component $i$, respectively. All these parameters are obtained from single adsorption isotherms.

In a multi-component system, competition for vacant adsorption sites in the surface of adsorbent occurs not only between the same molecules but also between different adsorbate species. This competition may act as the controlling factor for the adsorption process $[16,23]$ and such phenomenon is not captured by original extended Langmuir model. Recently, Kurniawan et al. [23] and Soetaredjo et al. [16] modified the extended Langmuir model by including fractional surface loading or coverage [23] and selectivity factor [16]. Since both epicatechin and catechin are organic compounds, the fractional surface loading approach by Kurniawan et al. [23] is more suitable to represent the binary adsorption data of this study. 
Since competition between catechin and epicatechin molecules for vacant adsorption sites in the activated carbon occurred during the adsorption process, catechin and epicatechin were adsorbed in certain amount, and the adsorption capacity of the activated for both adsorbates (binary) can be written as

$q_{m, b i n}=q_{m, 1} \theta_{1}+q_{m, 2} \theta_{2}$

Here $\theta_{1}$ and $\theta_{2}$ are the fractional loading of catechin and epicatechin, respectively, and $\theta_{1}+\theta_{2}=1$. The adsorption affinity parameter in Langmuir equation represents how strong an adsorbate molecule is attracted onto the surface of the adsorbent. In a binary system, the competition between different molecules weakens the adsorption potential of the adsorbate toward the surface of adsorbent, therefore, the affinity parameter of binary compounds can be written as:

$K_{L, 1(b i n)}=K_{L, 1} \exp \left(-\frac{\theta_{2}}{\theta_{1}}\right)$

$K_{L, 2(b i n)}=K_{L, 2} \exp \left(-\frac{\theta_{1}}{\theta_{2}}\right)$

where $K_{L, 1(\text { bin })}$ and $K_{L, 2(\text { bin })}$ are the affinity parameter of catechin and epicatechin in binary system, respectively. The final expressions of extended Langmuir model with inclusion of fractional loading concept are

$q_{e, 1}=\frac{q_{m, b i n} K_{L, 1(b i n)} C_{e, 1}}{1+K_{L, 1(\text { bin })} C_{e, 1}+K_{L, 2(\text { bin })} C_{e, 2}}$

$q_{e, 2}=\frac{q_{m, b i n} K_{L, 2(b i n)} C_{e, 2}}{1+K_{L, 1(\text { bin })} C_{e, 1}+K_{L, 2(\text { bin })} C_{e, 2}}$

The applicability of the modified extended Langmuir model was tested against the liquid phase binary adsorption data of catechin and epicatechin. The parameter $\grave{e}_{1}$ and $\grave{e}_{2}$ were obtained by the simultaneously fitting of Eqs. (9) and (10) using nonlinear least square method by minimizing the following objective function

$\mathrm{SSE}=\left[\frac{\sum\left(q_{\mathrm{exp}}-q_{\text {cal }}\right)^{2}}{n}\right]^{0.5}$

where $q_{\text {exp }}$ and $q_{c a l}$ are the actual amount and the calculated values of catechin and epicatechin adsorbed by activated carbon, respectively; $n$ is the total number of experimental data used in the fitting procedure.

Fig. 2 shows the 3D plots of binary adsorption of catechin and epicatechin at various initial concentrations and the model calculated by Eqs. (9) and (10). The fitted parameters $\theta_{1}$ and $\theta_{2}$ with calculate values of $q_{m,(\text { bin })}, K_{L, 1(\text { bin) }}$, and $K_{L, 2(\text { bin })}$ are summarized in Table 1. In this work an improvement was made in the fitting procedure of modified extended Langmuir model by Kurniawan et al. [23]. Both Eqs. (9) and (10) were simultaneously fitted by nonlinear least square method with $\theta_{1}$ and $\theta_{2}$ as the fitted parameters, with boundary condition of the fitting procedure as $\theta_{1}+\theta_{2}=1$. It is obvious that this fitting procedure improved the applicability of the modified extended Langmuir model in correlating the binary experimental data of catechin and epicatechin as indicated in Fig. 2.

The maximum amount of adsorbates adsorbed in binary system $\left(q_{m(b i n)}\right)$ was lower than in single system $\left(q_{m}\right)$ due to the effect of molecular competition between both adsorbate molecules. This competition was accommodated in the modified extended Langmuir by taking into account of fractional loading coverage. The fractional coverage of catechin $\left(\theta_{1}\right)$ and the maximum amount adsorbates adsorbed $\left(q_{m(b i n)}\right)$ decreased with increasing initial epicatechin concentration as shown in Table 1 . This result is consis- (a)

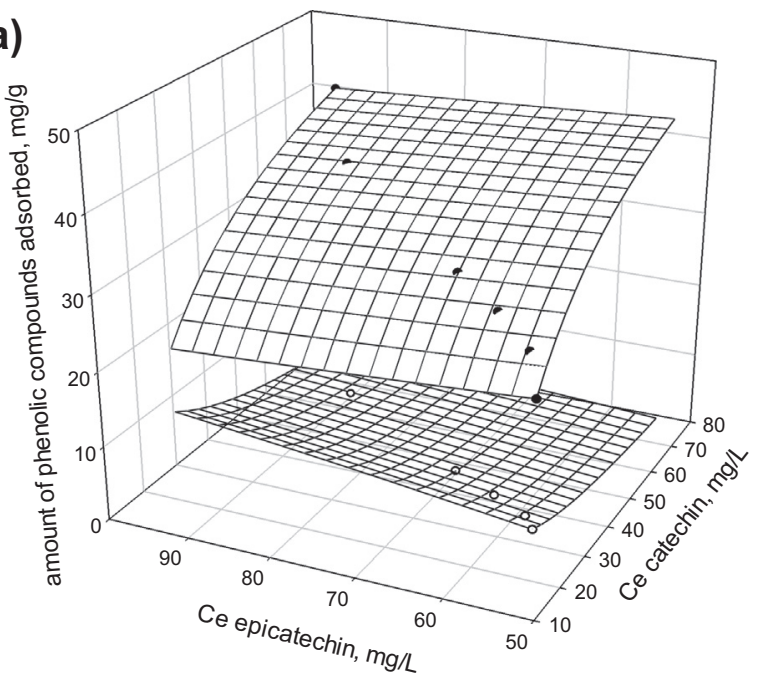

- adsorption experimental data of catechin - adsorption experimental data of epicatechin $\square$ modified extended Langmuir model

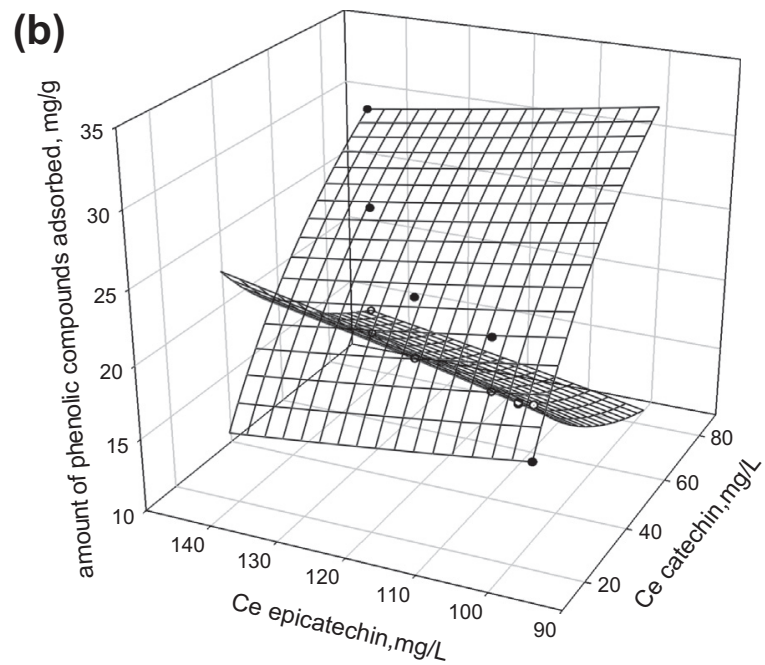

- adsorption experimental data of catechin - adsorption experimental data of epicatechin modified extended Langmuir model

Fig. 2. 3D plot of binary adsorption data and modified extended Langmuir model. (a) Catechin $100 \mathrm{mg} / \mathrm{L}+$ epicatechin $100 \mathrm{mg} / \mathrm{L}$, (b) catechin $100 \mathrm{mg} / \mathrm{L}+$ epicatechin $150 \mathrm{mg} / \mathrm{L}$.

tent with adsorption characteristics in single adsorption system that the adsorption capacity of epicatechin is less than that of catechin, therefore increasing the concentration of epicatechin in binary system caused the interaction of adsorbate molecules to become even higher and reduce the value of $q_{m(b i n)}$.

\subsection{Adsorption kinetics}

The effective design of an adsorption system requires information about the rate at which the organic compounds removal takes place in a given sorbent/solution system. Several adsorption kinetic models have been developed to describe the adsorption kinetics in liquid phase. The development of adsorption kinetic models mostly is based on fundamental approach to interfacial kinetics and its modifications [24]. Several models which have been developed 
Table 1

Fitted and calculated parameters for catechin and epicatechin adsorption at several initial concentrations.

\begin{tabular}{|c|c|c|c|c|c|c|}
\hline \multirow[t]{2}{*}{$\begin{array}{l}\text { Phenolic } \\
\text { compounds mixture }\end{array}$} & \multicolumn{2}{|c|}{$\begin{array}{l}\text { Fitted } \\
\text { parameter }\end{array}$} & \multicolumn{3}{|c|}{ Calculate parameter } & \multirow[t]{2}{*}{$R^{2}$} \\
\hline & $\theta_{1}$ & $\theta_{2}$ & $\begin{array}{l}q_{m,(b i n)} \\
\mathrm{mg} / \mathrm{g}\end{array}$ & $\begin{array}{l}K_{L, 1(\text { bin })} \\
\mathrm{L} / \mathrm{mg}\end{array}$ & $\begin{array}{l}K_{L, 2(\text { bin })} \\
\mathrm{L} / \mathrm{mg}\end{array}$ & \\
\hline $\begin{array}{l}\text { Catechin } 100 \mathrm{mg} / \\
\text { L + Epicatechin } \\
100 \mathrm{mg} / \mathrm{L}\end{array}$ & 0.632 & 0.368 & 57.1 & 0.0699 & 0.0075 & 0.998 \\
\hline $\begin{array}{l}\text { Catechin } 100 \mathrm{mg} / \\
\mathrm{L}+\text { Epicatechin } \\
150 \mathrm{mg} / \mathrm{L}\end{array}$ & 0.524 & 0.476 & 52.2 & 0.0499 & 0.0139 & 0.997 \\
\hline
\end{tabular}

based on this approach are Langmuir kinetics, first and second order, reversible first and second order, and irreversible reactions [24]. Another approach which is used to develop the kinetic models is based on assuming that surface reaction is the rate controlling step in sorption. Many simple and compact models have been proposed based on this approach and the famous and widely used models are pseudo-first (Lagergren) and pseudo-second order [24].

Pseudo-first order model which is also known as Lagergren equation is the earliest empirical model describing the rate of adsorption in a liquid phase system [25]. The differential form of this model is

$\frac{d q(t)}{d t}=k_{1}\left(q_{e}-q(t)\right)$

The integration of Eq. (12) with initial conditions: $q(t)=0$ at $t=0$ gives

$q(t)=q_{e}\left(1-\exp \left(-k_{1} t\right)\right)$

where $q(t)$ is the amount of adsorbate adsorbed at time $t(\mathrm{mg} / \mathrm{g})$, and $k_{1}$ is the rate constant $(1 / \mathrm{min})$.

Pseudo-second order was first proposed by Blanchard et al. [26]. This model assumes that direct adsorption/desorption (seen as chemical reaction) is the rate controlling step in the overall sorption kinetics [24], and has the differential form as

$\frac{d q(t)}{d t}=k_{2}\left(q_{e}-q(t)\right)^{2}$

Here $k_{2}$ is rate constant of pseudo-second order ( $\left.\mathrm{g} / \mathrm{mg} \min \right)$. Integration of Eq. (14) gives the following result

$q(t)=q_{e}\left(\frac{k_{2} q_{e} t}{1+k_{2} q_{e} t}\right)$
To obtain the parameters of pseudo-first and pseudo-second order equations, non-linear least square method was employed by fitting the kinetic experimental data with Eqs. (13) and (15) and the results are summarized in Table 2. Figs. 3 and 4 present the plots of catechin and epicatechin uptake as the function of time, respectively. The symbols represent the kinetic experimental data while the solid lines represent the pseudo-first and pseudo-second order kinetic models. As shown in Table 2, the values of $R^{2}$ obtained from the fitting of kinetic experimental data using both models were similar, however the pseudo-second order kinetic model represents kinetic experimental data better than the pseudo-first order since the predicted amount of adsorbate adsorbed in equilibrium condition was closer to that of the measured one. This is confirmed by the fact that from the values of fitting parameter $q_{e}$ of pseudo-second order model agree with the values of $q_{e}$ from kinetic experimental data. As mentioned by Plazinski et al. [24] that one of the potential advantages of using pseudo-second order kinetic model to correlate the adsorption kinetic experimental data is its small sensitivity to the influence of the random experimental error, especially for the fitting parameter $q_{e}$. Another advantage of using the pseudo-second order is that the value of fitted parameter $q_{e}$ can be obtained from the independent plot of kinetic adsorption experimental data [24,27].

In many adsorption kinetic studies [24,27-29], failure of the pseudo-first order in correlating adsorption kinetic experimental data is due to the theoretical interpretations of this equation. In pseudo-first order it is based on the common assumption that the overall sorption process is controlled by the rate of adsorption/desorption processes which is seen as a chemical reaction on the surface of adsorbent [24]. However in many cases, the rate of diffusion of solute into interior of the adsorbent also controls the adsorption mechanism and this phenomenon is not captured by the pseudo-first order model.

Table 2, Figs. 3 and 4 clearly indicate that the parameter $k_{2}$ plays a role as time scaling factor. At high $k_{2}$, shorter time is required to reach equilibrium. As can be seen in Table $2, k_{2}$ decreased with increasing initial concentration. A simple correlation between of $k_{2}$ and initial concentration of the adsorbate $\left(C_{o}\right)$ is given as follows:

$k_{2}=k_{2,0}+a \exp \left(-b C_{o}\right)$

where $k_{2, o}, a$ and $b$ are empirical constants. Plots of $C_{o}$ versus $k_{2}$ are given in Fig. 5. The fitted empirical constants for catechin are $k_{2, o}=0.0013 \mathrm{~g} / \mathrm{mg} \min , a=0.0194 \mathrm{~g} / \mathrm{mg} \min$, and $b=0.0092 \mathrm{~L} / \mathrm{mg}$, while for epicatechin are $k_{2, o}=0.0004 \mathrm{~g} / \mathrm{mg} \min , \quad a=0.0147 \mathrm{~g} /$ mg min, and $b=0.0207 \mathrm{~L} / \mathrm{mg}$.

Table 2

Fitted parameters of pseudo-first and pseudo-second order of catechin and epicatechin adsorption onto activated carbon NORIT nrs carbon Ea 0.5-1.5.

\begin{tabular}{|c|c|c|c|c|c|c|c|c|}
\hline \multirow[t]{2}{*}{ Phenolic compound } & \multirow[t]{2}{*}{$C_{o}, \mathrm{mg} / \mathrm{L}$} & \multirow[t]{2}{*}{$q_{e}, \mathrm{mg} / \mathrm{g}$, experiment } & \multicolumn{3}{|c|}{ Pseudo-first order } & \multicolumn{3}{|c|}{ Pseudo-second order } \\
\hline & & & $k_{1}, 1 / \mathrm{min}$ & $q_{e}, \mathrm{mg} / \mathrm{g}$ & $R^{2}$ & $k_{2}, \mathrm{~g} / \mathrm{mg} \min$ & $q_{e}, \mathrm{mg} / \mathrm{g}$ & $R^{2}$ \\
\hline \multirow[t]{6}{*}{ Catechin } & 101.3 & 43.3 & 0.0631 & 39.1 & 0.996 & 0.0022 & 43.4 & 0.997 \\
\hline & 122.5 & 43.9 & 0.0471 & 38.6 & 0.997 & 0.0014 & 44.3 & 0.998 \\
\hline & 139.8 & 44.5 & 0.0441 & 38.3 & 0.998 & 0.0013 & 44.3 & 0.999 \\
\hline & 158.7 & 44.7 & 0.0337 & 38.2 & 0.998 & 0.0008 & 46.1 & 0.998 \\
\hline & 203.6 & 45.3 & 0.0275 & 35.6 & 0.996 & 0.0007 & 44.2 & 0.997 \\
\hline & 251.9 & 46.1 & 0.0185 & 33.6 & 0.994 & 0.0004 & 45.1 & 0.996 \\
\hline \multirow[t]{6}{*}{ Epicatechin } & 100.5 & 21.2 & 0.1037 & 19.6 & 0.993 & 0.0086 & 20.9 & 0.994 \\
\hline & 118.4 & 21.9 & 0.1096 & 22.2 & 0.996 & 0.0083 & 23.6 & 0.998 \\
\hline & 141.2 & 23.2 & 0.0974 & 21.1 & 0.996 & 0.0069 & 22.8 & 0.996 \\
\hline & 161.5 & 25.4 & 0.0795 & 22.5 & 0.995 & 0.0053 & 24.5 & 0.996 \\
\hline & 201.7 & 28.2 & 0.0708 & 25.4 & 0.994 & 0.0040 & 27.9 & 0.997 \\
\hline & 252.3 & 28.9 & 0.0656 & 26.5 & 0.995 & 0.0034 & 29.3 & 0.995 \\
\hline
\end{tabular}



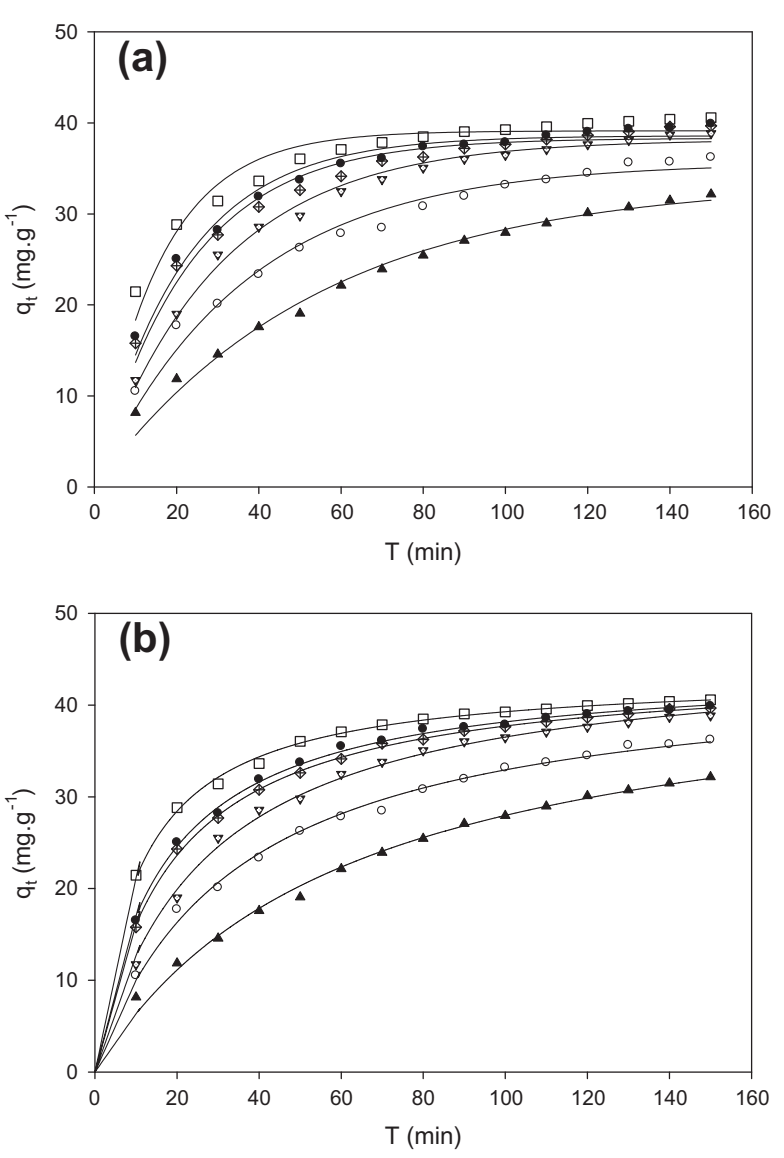

Fig. 3. Kinetic adsorption experimental data of catechin onto activated carbon NORIT nrs carbon Ea 0.5-1.5 at various initial concentration and plots of (a) pseudofirst order, and (b) pseudo-second order.

\subsection{Recover of phenolic compounds in sago waste effluent}

To verify the potential application of recovering phenolic compounds from sago waste effluent by adsorption, adsorption experiments using real sago waste effluent were also conducted. The adsorption of catechin and epicatechin from real sago waste effluent was conducted isothermally at $303.15 \mathrm{~K}$ under static condition. Prior to the adsorption experiment, the sago waste effluent was filtered to remove solid particles. The initial concentration of catechin and epicatechin in sago waste effluent was $321.8 \mathrm{mg} / \mathrm{L}$ and $158.2 \mathrm{mg} / \mathrm{L}$, respectively. The recovery of catechin and epicatechin in sago waste effluent is given in Table 3. From Table 3 it can be seen that the recovery of both phenolic compounds increases with increasing activated carbon mass due to the increase of adsorption active sites. At an adsorbent dose of $2 \%$, the recovery of catechin and epicatechin from sago waste effluent was $85 \%$ and $53 \%$, respectively. It can be seen that the amount of phenolic compounds adsorbed by the activated carbon from real waste sago effluent (Table 3 ) is less than that of the synthetic one (Fig. 2). In waste sago effluent, in addition to catechin and epicatechin other compounds such as protein and soluble starch are also present which compete for adsorption active sites resulting in the observed decrease of adsorption capacity toward catechin and epicatechin.

Reusability of adsorbent is crucial in industrial application. The recovery of catechin and epicatechin from activated carbon was performed by supercritical $\mathrm{CO}_{2}$ at $313.15 \mathrm{~K}$ and $26 \mathrm{MPa}$ under static and dynamic conditions. Details about the supercritical system can be found elsewhere [30]. At static condition, the recovery of catechin from activated carbon was only $1.2 \%$ while for epicatechin it was $14.5 \%$. This low recovery is consistent with the solubility
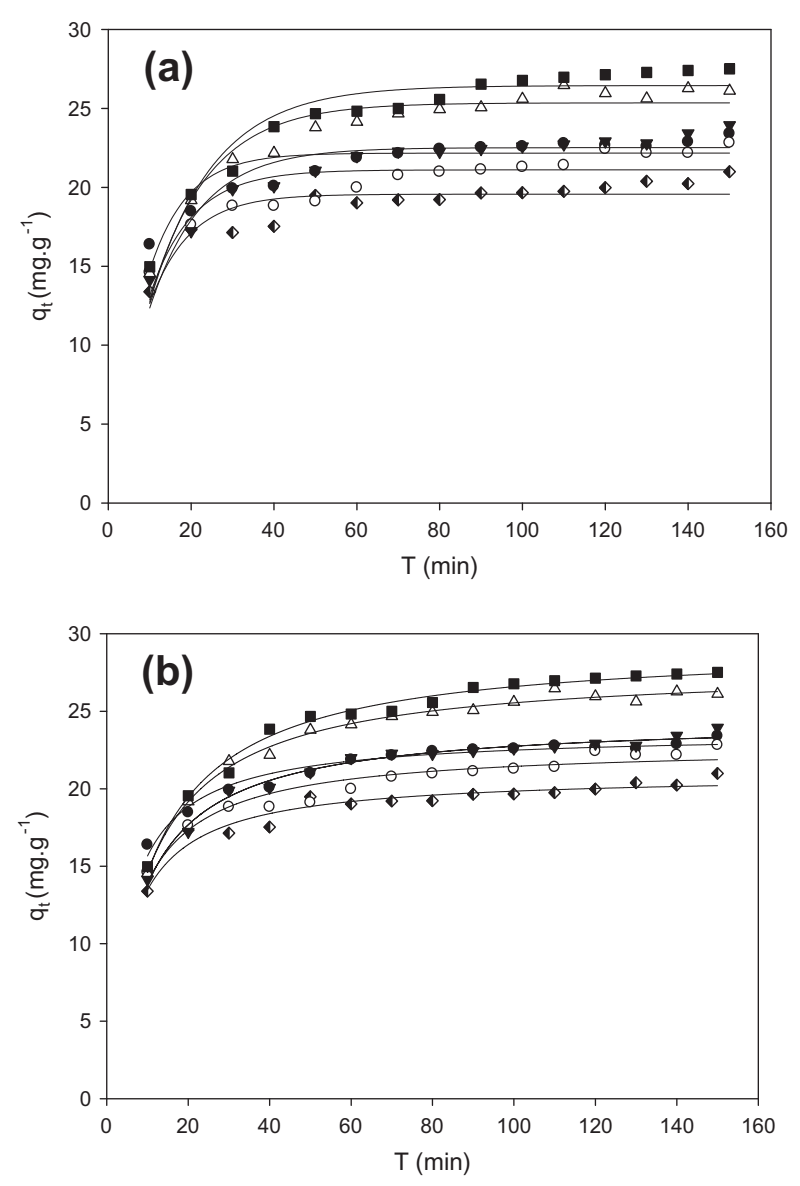

Fig. 4. Kinetic adsorption experimental data of epicatechin onto activated carbon NORIT nrs carbon Ea 0.5-1.5 at various initial concentration and plots of (a) pseudofirst order, and (b) pseudo-second order.

data of both phenolic compounds in supercritical $\mathrm{CO}_{2}$ under static condition $[30,31]$. In order to increase the recovery of catechin and epicatechin in supercritical $\mathrm{CO}_{2}$, dynamic extraction experiments were also conducted with flow rates of $\mathrm{CO}_{2}$ from 0.1 to $1 \mathrm{~kg} / \mathrm{h}$. By increasing $\mathrm{CO}_{2}$ flow rate from $0 \mathrm{~kg} / \mathrm{h}$ (static mode) to $0.1 \mathrm{~kg} / \mathrm{h}$, the recovery increased from $1.2 \%$ to $2.3 \%$ and from $14.5 \%$ to $27 \%$ for catechin and epicatechin, respectively. Maximum recovery (catechin 9.7\% and epicatechin $87.3 \%$ ) was achieved at a $\mathrm{CO}_{2}$ flow rate of $0.7 \mathrm{~kg} / \mathrm{h}$. Further increase of $\mathrm{CO}_{2}$ flow rate to $1 \mathrm{~kg} / \mathrm{h}$ had negligible effect on the recovery both compounds.

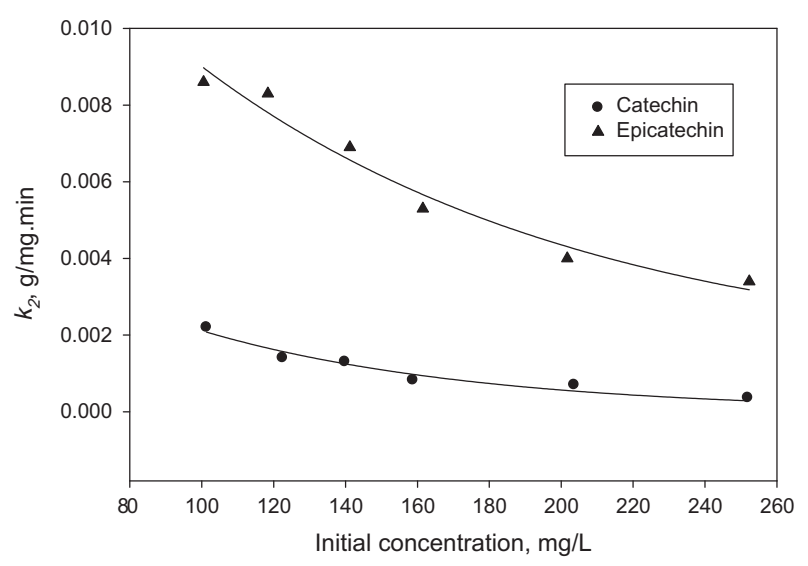

Fig. 5. Correlation between $C_{o}$ and $k_{2}$. 
Table 3

Adsorption of catechin and epicatechin from sago waste effluent.

\begin{tabular}{|c|c|c|c|c|c|c|c|c|}
\hline $\begin{array}{l}C_{o, 1} \text { catechin, } \mathrm{mg} / \\
\mathrm{L}\end{array}$ & $\begin{array}{l}C_{o, 2} \text { epicatechin, mg/ } \\
\mathrm{L}\end{array}$ & $\begin{array}{l}m \text {, mass of activated carbon, } \\
\mathrm{g}\end{array}$ & $\begin{array}{l}C_{e, 1}, \mathrm{mg} / \\
\mathrm{L}\end{array}$ & $\begin{array}{l}C_{e, 2}, \mathrm{mg} / \\
\mathrm{L}\end{array}$ & $\begin{array}{l}q_{e, 1}, \mathrm{mg} / \\
\mathrm{g}\end{array}$ & $\begin{array}{l}q_{e, 2}, \mathrm{mg} / \\
\mathrm{g}\end{array}$ & $\begin{array}{l}\text { \% Recovery } \\
\text { catechin }\end{array}$ & $\begin{array}{l}\text { \% Recovery } \\
\text { epicatechin }\end{array}$ \\
\hline \multirow[t]{8}{*}{321.8} & 158.2 & 0.112 & 274.4 & 143.3 & 42.3 & 13.3 & 14.7 & 9.4 \\
\hline & & 0.483 & 141.2 & 113.8 & 37.4 & 9.2 & 56.1 & 28.1 \\
\hline & & 0.689 & 110.3 & 103.8 & 30.7 & 7.9 & 65.7 & 34.4 \\
\hline & & 0.921 & 99.8 & 100.2 & 24.1 & 6.3 & 68.9 & 36.7 \\
\hline & & 1.104 & 95.5 & 96.4 & 20.5 & 5.6 & 70.3 & 39.1 \\
\hline & & 1.328 & 85.4 & 93.1 & 17.8 & 4.9 & 73.5 & 41.1 \\
\hline & & 1.573 & 71.2 & 87.4 & 15.9 & 4.5 & 77.7 & 44.7 \\
\hline & & 1.921 & 48.3 & 74.2 & 14.2 & 4.3 & 84.8 & 52.3 \\
\hline
\end{tabular}

Note: volume of sago waste effluent $100 \mathrm{~mL}$.

Low recovery of phenolic compound, especially catechin is caused by the difference in the polarity between the solute (phenolic compound) and the solvent (supercritical $\mathrm{CO}_{2}$ ). Catechin is highly polar while supercritical $\mathrm{CO}_{2}$ is non-polar. In order to increase the polarity of supercritical $\mathrm{CO}_{2}$, ethanol as co-solvent (5$25 \%$ ) was used in this study. By adding $5 \%$ ethanol at a $\mathrm{CO}_{2}$ flow rate of $0.7 \mathrm{~kg} / \mathrm{h}$, the recovery of catechin increased almost two fold (from $9.7 \%$ to $18.2 \%$ ), and while for epicatechin the recovery reached 95.7\%. Increasing the percentage of co-solvent increased the recovery of both compounds. For epicathecin the maximum recovery was $99.2 \%$ at $20 \%$ of co-solvent. Further increase in co-solvent concentration had negligible effect on the recovery of epicatechin. The un-recovered epicatechin may be strongly bound on carbon surface or epicatechin molecule may be adsorbed inside small or ultra micropore so it could not be desorbed by supercritical $\mathrm{CO}_{2}$. At $30 \%$ co-solvent, the recovery of catechin was $93.1 \%$. Since further increase of co-solvent concentration changed supercritical condition into subcritical, therefore maceration $(303.15 \mathrm{~K}$, $24 \mathrm{~h}$ ) was used to obtain maximum removal of catechin (97.8\%) and epicatechin (99.4\%).

\section{Conclusion}

The recovery of catechin and epicatechin from sago waste effluent by adsorption onto activated carbon followed by supercritical $\mathrm{CO}_{2}$ desorption was demonstrated in this work. To study the kinetic and equilibria of adsorption, synthetic aqueous catechin and epicatechin solution was used instead of sago waste effluent. The adsorption equilibria and kinetic were obtained isothermally at $303.15 \mathrm{~K}$ in static mode condition. The adsorption equilibria of single and binary system were modeled using Langmuir and modified extended Langmuir, respectively. It was found that both of models could represent the experimental data well. In adsorption kinetic experiments, the well-known pseudo-first and pseudo-second models were employed to correlate the experimental data. The pseudo-second model gave better representation of experimental data than the pseudo-first model. The effect of initial concentration on the value of fitting parameters $k_{1}$ and $k_{2}$ was also studied. The results indicate that $k_{2}$ plays a role as time scaling factor, at high $k_{2}$, shorter time is required to reach equilibrium.

Adsorption using real sago waste effluent followed by supercritical $\mathrm{CO}_{2}$ extraction indicates that this method has potential application in recovery catechin and epicatechin in industrial scale. Ethanol as co-solvent was required to obtain high recovery of catechin from the activated carbon.

\section{References}

[1] M.A. Soobrattee, V.S. Neergheen, A. Luximon-Ramma, O.I. Aruoma, T. Bahorun, Phenolics as potential antioxidant therapeutic agents: mechanism and actions, Mutat. Res. 579 (2005) 200-213.

[2] L. Yu, K. Zhou, Antioxidant properties of bran extracts from "platte" wheat grown at different locations, Food Chem. 90 (2004) 311-316.
[3] P. Vitaglione, A. Napolitano, V. Fogliano, Cereal dietary fibre: a natural functional ingredient to deliver phenolic compounds into the gut, Trends Food Sci. Technol. 19 (2008) 451-463.

[4] A.R. Rechner, M.A. Smith, G. Kuhnle, G.R. Gibson, E.S. Debnam, S.K.S. Srai, K.P. Moore, C.A. Rice-Evans, Colonic metabolism of dietary polyphenols: influence of structure on microbial fermentation products, Free Radical Biol. Med. 36 (2004) 212-225.

[5] A.R. Rechner, G. Kuhnle, P. Bremner, G.P. Hubbard, K.P. Moore, C.A. Rice-Evans, The metabolic fate of dietary polyphenols in humans, Free Radical Biol. Med. 33 (2002) 220-235

[6] O. Pourali, F.S. Asghari, H. Yoshida, Production of phenolic compounds from rice bran biomass under subcritical water conditions, Chem. Eng. J. 160 (2010) 259-266.

[7] H. Epstein, Cosmeceuticals and polyphenols, Clin. Dermatol. 27 (2009) 475478

[8] S.M. Anthonysamy, N.B. Saari, K. Muhammad, F.A. Bakar, Browning of sago (Metroxylon sagu) pith slurry an influenced by holding time, $\mathrm{pH}$ and temperature, J. Food Biochem. 28 (2004) 91-99.

[9] A.T. Pei-Lang, A.M.D. Mohamed, A.A. Karim, Sago starch and composition of associated components in palms of different growth stages, Carbohyd. Polym. 63 (2006) 283-286.

[10] M. Ahmaruzzaman, Adsorption of phenolic compounds on low-cost adsorbents: a review, Adv. Colloid Interfaces 143 (2008) 48-67.

[11] K. Baransi, Y. Dubowski, I. Sabbah, Synergetic effect between photocatalytic degradation and adsorption processes on the removal of phenolic compounds from olive mill wastewater, Water Res. 46 (2012).

[12] A. Dabrowski, P. Podkoscielny, Z. Hubicki, M. Barczak, Adsorption of phenolic compounds by activated carbon - a critical review, Chemosphere 58 (2005) 1049-1070.

[13] J. Qi, Y. Guo, H. Xu, Adsorption of phenolic compounds on micro- and mesoporous rice husk-based active carbons, Mater. Chem. Phys. 87 (2004) $96-$ 101.

[14] C. Michailof, G.G. Stavropoulos, C. Panayiotou, Enhanced adsorption of phenolic compounds, commonly encountered in olive mill wastewaters, on olive husk derived activated carbons, Bioresour. Technol. 99 (2008) 64006408.

[15] M.L. Soto, A. Moure, H. Dominguez, J.C. Parajo, Recovery, concentration and purification of phenolic compounds by adsorption: a review, J. Food Eng. 105 (2011) 1-27.

[16] F.E. Soetaredjo, A. Kurniawan, L.K. Ong, S. Ismadji, Incorporation of selectivity factor in modeling binary component adsorption isotherms for heavy metalsbiomass system, Chem. Eng J. 219 (2013) 137-148.

[17] C.H. Giles, D. Smith, A. Huitson, A general treatment and classification of the solute adsorption, I., Theor. J. Colloid Interface Sci. 47 (1974) 755-765.

[18] C.H. Giles, A.P. D'Silva, I.A. Easton, A general treatment and classification of the solute adsorption isotherm, II, J. Colloid Interface Sci. 47 (1974) 766778.

[19] Y. Ding, D. Jing, H. Gong, L. Zhou, X. Yang, Biosorption of aquatic cadmium (II) by unmodified rice straw, Bioresour. Technol. 114 (2012) 20-25.

[20] H. Muhamad, H. Doan, A. Lohi, Batch and continuous fixed-bed column biosorption of $\mathrm{Cd}^{2+}$ and $\mathrm{Cu}^{2+}$, Chem. Eng. J. 158 (2010) 369-377.

[21] C.G. Rocha, D.A.M. Zaia, R.V.d.S. Alfaya, A.A.d.S. Alfaya, Use of rice straw as biosorbent for removal of $\mathrm{Cu}(\mathrm{II}), \mathrm{Zn}(\mathrm{II}), \mathrm{Cd}(\mathrm{II})$ and $\mathrm{Hg}(\mathrm{II})$ ions in industrial effluents, J. Hazard. Mater. 166 (2009) 383-388.

[22] K.K.H. Choy, J.F. Porter, G. McKay, Langmuir isotherm models applied to the multicomponent sorption of acid dyes from effluent onto activated carbon, J. Chem. Eng. Data 45 (2000) 575-584.

[23] A. Kurniawan, H. Sutiono, N. Indraswati, S. Ismadji, Removal basic dyes in binary system by adsorption using rarasaponin-bentonite: revisited extended Langmuir model, Chem. Eng. J. 189-190 (2012) 264-274.

[24] W. Plazinski, W. Rudzinski, A. Plazinska, Theoretical models of sorption kinetics including a surface reaction mechanism: a review, Adv. Colloid Interfaces 152 (2009) 2-13.

[25] S. Lagergren, Zur theorie der sogenannten adsorption geloster stoffe Kungliga Svenska Vetenskapsakademiens, Handlingar 24 (1898) 1-39.

[26] G. Blanchard, M. Maunaye, G. Martin, Removal of heavy metals from waters by means of natural zeolites, Water Res. 18 (1984) 1501-1507. 
[27] A.N. Kosasih, J. Febrianto, J. Sunarso, Y.-H. Ju, N. Indraswati, S. Ismadji, Sequestering of $\mathrm{Cu}(\mathrm{II})$ from aqueous solution using cassava peel (Manihot esculenta), J. Hazard. Mater. 180 (2010) 366-374.

[28] A. Kurniawan, H. Sutiono, Y.-H. Ju, F.E. Soetaredjo, A. Ayucitra, A. Yudha, S. Ismadji, Utilisation of rarasaponin natural surfactant for organo-bentonite preparation: application for methylene blue removal from aqueous effluent, Micropor. Mesopor. Mater. 142 (2011) 184-193.

[29] A. Kurniawan, S. Ismadji, Potential utilization of Jatropha curcas L press cake residue as new precursor for activated carbon preparation: application in methylene blue removal from aqueous solution, J. Taiwan Inst. Chem. Eng. 42 (2011) 826-836.

[30] F.E. Soetaredjo, S. Ismadji, Y.-H. Ju, Measurement and modeling of epicatechin solubility in supercritical carbon dioxide fluid, Fluid Phase Equilib. 340 (2013) $7-10$.

[31] F.E. Soetaredjo, S. Ismadji, M.J. Liauw, Y.-H. Ju, Catechin sublimation pressure and solubility in supercritical carbon dioxide, Fluid Phase Equilib. (2013). submitted for publication. 